\title{
Consequences Of Drug Abuse On Spouses Of Drug Addicts In Karachi
}

\author{
Syeda Farhana Sarfaraz \\ Department of Social Work \\ University of Karachi
}

\begin{abstract}
The issue of drug addiction or abuse is often over shadowed by the many of the human development problem such as poverty, illiteracy, lack of basic health care. But the fact is drug abuse is rapidly growingly in Pakistan and South Asia in general. Pakistan is the worst victim of narcotics trade in South Asia region. According to an estimate about 20 tons of heroin consume with in Pakistan annually. One addict in a family affects several other members the number of people suffering directly or indirectly runs into many more millions. This is a fastest growing problem which cuts across class, rural, urban, provincial and religious boundaries. A number of socio-economic problems, large disparities between income groups, poverty, corruption, lack of political will and above all easy access to drugs are known to be linked to drug abuse and crime. In fact it is a problem of social disorganization with multidimensional implication on the individual and other family members. The overall purpose of the study was to examine the consequences of drugs abuse on spouses of the drug uses in contemporary society. The problem of drug abuse and drug trafficking has assumed transnational character in recent years and no nation can claim to be free from this issue.
\end{abstract}

\section{تلخيص. مقالر}

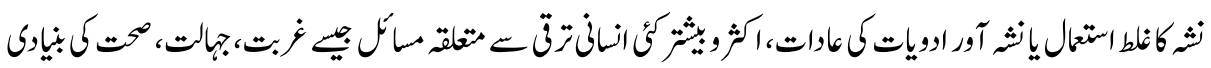

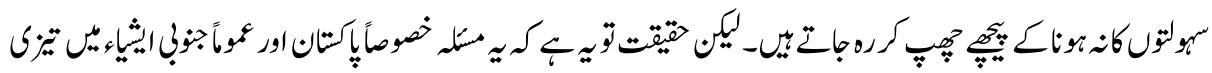

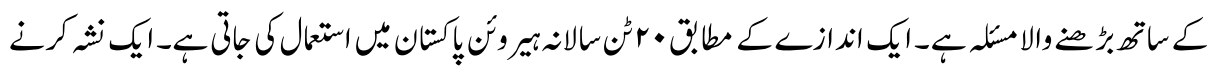

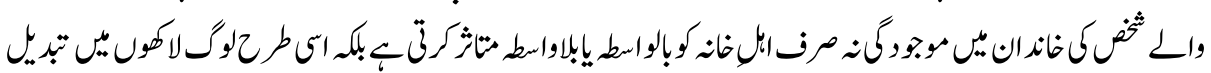

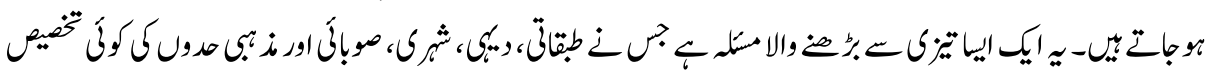

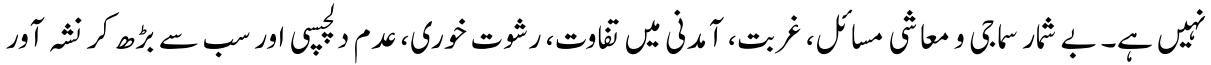

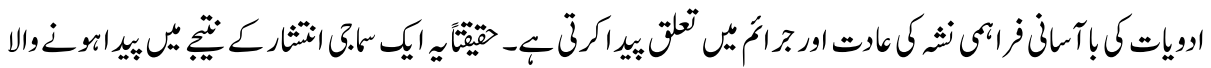

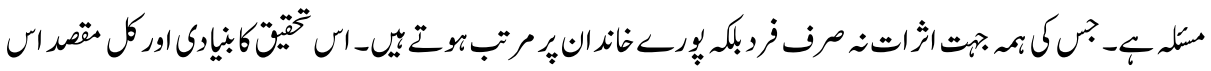

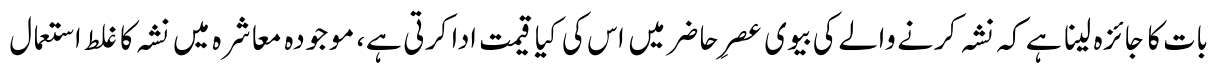

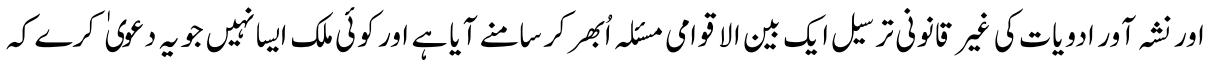

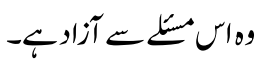




\section{Introduction}

Drug is derived from the French word "drogue" means any dry herb. Generally, a drug is defined as any substance used for the purpose of diagnosis prevention, relief or cure of a disease. WHO world health organization developed a broad definition that is:

"A drug is any substance other than those required for the maintenance of normal health, which when taking into living organization, may modify one or more of its function."'(WHO, 1969)

Drug abuse is taking a drug for reasons other than medical, in any amount, strength, frequency or manner that damages the physical and mental functioning. In this regards WHO introduced the term "harmful use":

"A pattern of psychoactive drug use, that causes damages to health, either mental or physical. It is also notified that, the harmful use of a drug by an individual often has adverse effects on the drug user's family, the community and society in general." (WHO, 1993)

The definition of term "drug" is product of social customs and law, both of which change over time. Societies throughout the world differ considerably with respect to the rules they follow to classify specifies such a drugs, poisons, foods, beverages, medicines and herbs. Social scientist in the behavioral tradition commonly objects to the diseases approach to drug addiction as having little clinical or scientific utility. The modern psychologists view is that addictive behavior and as such should obey the rules that govern the learning. Now a day's some drugs experts refers to think of addiction as a behavior compulsion, without reference to withdrawal effects at all.

Drug addiction therefore be defined as the compulsive use of one or more of the five substances (opium, cannabis, hallucinogens, stimulants, sedatives and solvents) resulting in the mental or physical dependence of the abuser on the substance he used.

"Addiction will be defined a behavior pattern characterized by an ongoing and over whelming pre occupation with use of a drug and securing of its supply." (Kerivanek, 1982)

Conceptually an addict is a person who has surrendered himself to the habitual taking of drug without medical supervision to the extent that he gets into physical agony and mental trauma if the drug is suddenly withdrawn. A drug addicts is a person who suffers chemical discrepancy that is the person has an overwhelming urge to use a drug regardless of the consequences. By definition an addict: 
"A person physically or mentally dependent on any narcotic drug ,or psychotropic substances or a person who habitually use narcotic drugs or psychotropic substances." (Emmanuel, 2002)

There are many factor contributing for drug abuse, most important of them are: curiosity or to have some pleasure, peer group or influence of friends, to overcome boredom, depression or fatigue, lack of love, various kinds of frustrate in life due to poverty unemployment social in justice inequality corruption, parental relations, family feuds, or unmet needs and hopes, urbanization, favoritism prevail in society to the exclusion of merit and easy availability of illegal drugs. Drug addiction definitely leads to an increase on crime. While a male drug addict turns to robbery etc, the female turns to prostitution. The crimes are economically based and committed to support drug abuse. It is not a symptom of an underlying disorder but a describable primary illness. The illness produces a negative impact on all areas of affected person's life. The family members of drug user go through a series of role changes.

A person involving in drug abuse shows certain symptoms in his physical and mental conduct and behavior like, loss of interest in daily routine and sports, loss of weight and appetite, unsteady gait, slurring of speech reddening and becomes puffiness of eyes, fresh injection sites, blood stains on clothes, presence of needles, syringes, strange friends at home, nausea, vomiting and body pain, drowsiness, lethargy, anxiety, profuse sweating, mood changes, impaired memory, preference for suicide, spending long hours in toilet and missing of articles and money from home. Drug abuse and trafficking are closely related problems. A drug peddler an addict by virtue of his job while a drug addict become a drug peddler force by the financial need to find money for his habit. Drug mafia's increasing involvement in terrorism, illegal arms trade and laundering of huge sums of money has been responsible for economic and political instability in our country.

Drug abuse is a global phenomenon for reasons of similarities of human nature everywhere, as well as the shrinking of the globe due to the rapid advancements made in the field of transport and communication. It has far reaching impacts on the economy, society, politics, and even on the international relation around the globe. The social functioning of the individual is impaired due to poor health, loss of income and isolations from the society. The growth and development of the family is blocked and social environment of the community is adversely affected. The abuse of drugs has badly affected many capable, enlightened, healthy, active and smart members of society. Needle and syringe is common practice, facilitates the rapid spread of HIV/AIDS. Relatively little research has been done on the consequences of drug abuse in the country. There is lack of official statics or reliable reports available on the impact of drug abuse, drug related death/births, and drug related crimes, violence and terrorist act. Recent trend suggest a shift from inhaling and smoking heroin to injection of drugs, particularly 
pharmaceutical drugs, bearing the high risk of HIV/AIDS and others epidemic related to IDU. Heroine use alone is responsible for the epidemic number of new cases of HIV/AIDS, hepatitis, BBD (blood born diseases), STDs (Sexually transmitted diseases) and STIs (Sexually transmitted infection) hepatitis and drugs addicted infants born every year.

Pakistan is confronting with a significant drug abuse problem since last four decade. First of all the dimension of drug problem in Pakistan is multifarious. People of the world are only aware of that the role of Pakistan in drug trafficking as a conduit-pipe due to its geographical condition. Unfortunately, the world at large, and ironically even the people of Pakistan, is not aware of an equally disastrous fact of the problem: The problem of drug abuse in the country itself, which has attained alarming proportions without any one realizing it. Secondly the problem of heroin addiction, which once could be termed as a by-product of drug trafficking through Pakistan, has become major challenge for the government and philanthropist reforms of this age.

Poor social and economic conditions in Pakistan have a broad impact on overall health situation and increase vulnerability of the general population to drug problems. It has serious Implication on the health and happiness of the individual, the family, the community and society at large. For example these who are poor often have the least access to education and social services, therefore least access to the information and tools which might help or protect them from drug abuse. The frustration related to poverty drives people to abuse drugs.

On the other hand, drug addicts have little access to effective treatment with a few exception, the services provided by drug treatment facilities are limited to the management of acute withdrawal symptoms of 10_15 day's duration. Only few well established NGO's and private clinics offers comprehensive treatment packages including rehabilitation and social reintegration services, but these are too expensive for the average street addicts to a access.

In Pakistan, awareness of the drug abuse problem has developed quite recently. In the past there was very little work done in the form of properly planned surveys or collection of statistical date on this subject. According to the National Survey on Drug Abuse (NCB 1993), there were about 3.01 million drug addicts in Pakistan, signifying an annual increase of $7 \%$ in comparison with statistics obtained from a similar survey conducted in 1986.

A study carried out in Pakistan (UNODC, 2000) to assess drug abuse trends identified that cannabis is the most commonly abused drug, followed by heroin out of 5 million addicts. According to the study, there were about 60,000 Injecting Drug Users (IDUs) in 
the country, with the figure projected to reach 180,000 by end-2004. Most of the IDUs resort to needle sharing and are totally unaware of the health hazards associated with the practice.

The National Assessment Report on Problem Drug Use in Pakistan (UNODC, 2006) estimates that:

"There are 628,000 opiate users. Of these, around 482,000 (77 percent) are heroin users. Given the massive increase of opium and heroin production in Afghanistan, the relative stability in the numbers of the opiate abusing population over the past six years is a notable achievement. However, the number of injecting drug users (IDUs) in 2006 is estimated at 125,000, double the estimated figure for 2000. This is a cause for concern particularly in terms of the HIV/AIDS transmission risk."

The prevalence rates for opiate use range from 0.4 percent in the provinces of Punjab and Sindh to 0.7 percent in the North-West Frontier Province and 1.1 percent in Baluchistan. The latter two provinces share a direct border with Afghanistan. While the overall rate of abuse has not changed much in Pakistan, the proportion of drug users who inject has increased from 15 percent in 2000 to 29 percent in 2006 as shown in table No 1.

Table No1

Prevalence of opiate use in Pakistan by province

\begin{tabular}{|c|c|c|c|c|c|}
\hline & $\begin{array}{c}\text { Prevalence } \\
(\% \text { of } \\
\text { Population })\end{array}$ & $95 \%$ CI & Numbers & $\begin{array}{c}\text { IDU } \\
\text { Prevalence }\end{array}$ & $\begin{array}{c}\text { IDU } \\
\text { Numbers }\end{array}$ \\
\hline NWFP & 0.7 & $0.5-0.9$ & 90,000 & 0.06 & 8,000 \\
\hline Punjab & 0.4 & $0.2-0.6$ & 200,000 & 0.2 & 100,000 \\
\hline Sindh & 0.4 & $0.2-0.6$ & 87,000 & 0.2 & 44,000 \\
\hline Baluchistan & 1 & $0.8-1.2$ & 45,000 & 0.1 & 4,500 \\
\hline $\begin{array}{c}\text { Overall } \\
\text { Pakistan }\end{array}$ & 0.7 & $0.4-1$ & 628,000 & 0.14 & 125,000 \\
\hline
\end{tabular}

Source UNODC 2006

The National Assessment Report also estimates that:

"The majority of opiate users (77 percent) were using heroin while the remainder were using opium and other opiates. Most of the opiate users were multiple users, i.e., they were using more than one substance at any given time or during a day. Many drug users reported facing serious health and social problems. Around 8 percent reported having $H I V$ infection, 18 percent reported having Tuberculosis and 11 percent reported 
Hepatitis $C$ infection. The average age of opiate users is 35.5 years. Countrywide, up to 33 percent of the drug users were between 31 to 40 years old, while in Punjab and Singh up to 40 percent of the drug users were between 16 and 30 years old. The majority of opiate users (72 percent) were still living at home. While 38 percent had no education, 25 percent had up to primary and one third up to high school education. Around one third of the opiate users were unemployed, while the remainder had been supporting them through casual work (39 percent), or had been working part or full time (15 percent and 7 percent respectively). Therefore, contrary to conventional assumptions, a significant proportion of opiate users can and do participate in economic activity.",

National drug abuse assessment study of Pakistan 2008 to 2011 done by ANF (Anti Narcotics Force) highlight the following facts but it was an assessment report not a survey.

1. Among both males and females in the age limit of 15-45 years there are 50000000 regular heroine users.

2. Heroine is the most commonly in the terms of lifetime use prevalence, followed by alcohol.

3. Heroine is equally popular in urban and rural areas.

4. Heroine abuses on the average have six years of education $43 \%$ of the total number are unemployed and $26 \%$ are engaged in full time employment.

5. $40 \%$ of the heroine users fall in the age bracket of 25-35 years.

6. $47 \%$ belongs to skilled and unskilled labour $85 \%$ agricultural workers and 3\% are students.

7. $22 \%$ sustains themselves through casual work $18 \%$ enjoying family supports $16 \%$ are beggars $13 \%$ are drugs paddlers $11 \%$ resort to petty thefts and other criminal activities.

8. It has been found that women comprise only $3 \%$ and most abused drugs are psychotropic substances.

9. $77 \%$ are daily heroine users most of the hardcore drugs users consist of multidrug consumers a poly drug users.

$10.73 \%$ of the heroines users smoke or inhale the drugs $15 \%$ are IDUs.

11. $64 \%$ of the users having difficulties in getting treatment. ${ }^{3}$

This is the whole scenario, which is necessary to understand the menace of drugs and drug abuse implication on spouses of drug abuser. Addiction often creates interpersonal problems for all family members especially for spouses for example continuous conflict with each other, conflict over money, emotional trauma, cheating, separation, and health risk etc. This study will help to reflect the real picture and intensity of the problem. 


\section{Objectives}

- To study the demographic, socio economic profile and the living conditions drug user's family.

- $\quad$ To know about the consequences of the drug abuse on spouses of drug users.

\section{Methodology}

It was an exploratory study conducted on the families of drug users came for treatment and follow up in a treatment centre situated in Karachi. The total numbers of 46 respondents (spouses) were included in this study on the basis of willingness. In the light of objectives a questionnaire was prepared and pretesting was carried out. Out of 46 respondent six questionnaires were not filled completely and were excluded from the analysis so that final analysis was conducted on 40 respondents.

\section{Demographic Profile}

There are 52\% women interviewed were married to IDU (injecting drug user), while the husbands of the remaining $48 \%$ did not inject as shown in table No 2 .

Table No 2

Husband was IDU/DU at the time of marriage.

\begin{tabular}{|l|c|c|}
\hline \multicolumn{1}{|c|}{ Response } & Number & Percentage \\
\hline IDU (inject able drug user) & 21 & 52.50 \\
\hline DU & 19 & 47.50 \\
\hline Total & $\mathbf{4 0}$ & $\mathbf{1 0 0 . 0 0}$ \\
\hline
\end{tabular}

The respondents were falling into the reproductive age bracket as shown in table No 3 , and have an average of four children.

Table No 3

Age of spouses

\begin{tabular}{|l|c|c|}
\hline Responses & Number & Percentage \\
\hline $21-25$ & 10 & 25.00 \\
\hline $26-30$ & 15 & 37.50 \\
\hline $31-35$ & 6 & 15.00 \\
\hline $36-40$ & 7 & 17.50 \\
\hline $41-45$ & 2 & 5.00 \\
\hline Total & $\mathbf{4 0}$ & $\mathbf{1 0 0 . 0 0}$ \\
\hline
\end{tabular}


While the table No 4 shows that (58\%) lived in joint family with in-laws and a considerable number $42 \%$ lived separately.

Table No 4

Type of family

\begin{tabular}{|l|c|c|}
\hline \multicolumn{1}{|c|}{ Response } & Number & Percentage \\
\hline Single family system & 17 & 42.50 \\
\hline Joint family system & 23 & 57.50 \\
\hline Total & $\mathbf{4 0}$ & $\mathbf{1 0 0 . 0 0}$ \\
\hline
\end{tabular}

$65 \%$ had received no formal education, with a small percentage had obtained primary education. Most of the women had been married at an early age.

\section{Economical Consequences}

The financial impact on the wives of drug users is extreme, particularly for those who do not live in joint family system. 52\% women earned up to Rs.5000/= each month. On the other hand, $46 \%$ of drug user's husbands worked regularly but regularly asked their wives for money to buy drugs. Spouses were primarily responsible for fulfilling basic household expenses including food, clothing, rent and associated utilities. They were also responsible for bearing the cost of education of their children and the financial burden of getting young daughters marriage.

Approximately $48 \%$ of the spouses had money regularly to buy food, while $2 \%$ borrowed occasionally. Unfortunately borrowing money proved to an extremely humiliating process for many women as people were openly reluctant to lend money to them, knowing that they would not able to pay back the loan. Inadequate nutrition may negative effect of an insufficient household income including those who living in joint family system.

All spouses expressed a desire to be able to educate their children so that they would have a better future. The inability to educate children was another negative consequence of drug use. Many of the respondents sent their children to Govt. schools. But substantial number of women couldn't afford to educate their children at all.

Where about $25 \%$ of the respondent that they are aware of their husband's drugs habit prior to getting married. Many spouses stated that their husbands had received the free, month long treatment numerous times without success but they seek proper treatment for their husband which is affordable. None of the women interviewed currently worked or admitted to working in the sex industry, only one woman admitted to considering sex work as an alternative to starvation. 


\section{Health related Consequences}

The spouse and the children of the IDU's ( injecting drug users) vulnerable to an impact on their health and at great risk of HIV/Aids B and C sexually transmitted diseases. Violence is very much a part of the daily lives of women married to drugs, usually when the drug users was under influence of drugs, or when he needed to buy drugs. About $65 \%$ of the women interviewed had heard of HIV/AIDS and $25 \%$ had no accurate understanding of its modes of transmission. As mentioned earlier $42 \%$ of the women interviewed were married to IDU's but majority of them did not use condoms. Husbands willingness was the single reason for not used a condom, making spouse extremely vulnerable to HIV infection.

\section{Social Consequences}

The financial and emotional stresses of such situation were borne entirely by the spouse of drug users, and often had serious psychological impacts. Due to this, some women admitted to hiding their husband's drug use from the community and in some cases their HIV positive status was also critical barriers to go the treatment.

A majority of women mentioned that they felt extremely isolated from their community. Isolation of women caused by male drug use often meant there was little or no support available to spouses when needed. Women whose husbands were HIV positive, or who were HIV positive themselves were unable to tell their communities, or even their families in fear of being further ostracized.

\section{Psychological Consequences}

The financial, physical health and social impact on the spouses of drug user could measure and observed, the psychological impact of drug use was more difficult to ascertain.

The most obvious issue was a feeling of helplessness and defeat caused by in inability to provide proper care for children. Most the women regretted not being able to send their children to school. However, they knew that their young children had to work in order to supplement household income.

This combination of not being able to provide food and education to their children was one of the most stresses of their life. Mothers also worried about protecting their children from falling into cycle of drug abuse. It is important to note that the psychological impact of the drug use on women can lead to an unstable family environment for other young children in the household. The social and economic changes that are brought about due to 
a father's drug use may weaken the sense of family, which is an important factor for the development of young children. The combination of a negative role model such as a drug using father, and a mother who is immersed in trying to meet financial obligations along with the social isolation of family could have a serious impact on the children in a household which could further perpetuate the cycle of drug abuse.

\section{Conclusions}

The main issue that was mentioned by nearly all women interviewed was the lack of proper treatment for their husbands. The women unanimously agreed that standard of one month treatment was extremely ineffective and the need for slandered treatment. Treatment centre should include some services like reproductive health, family planning, and on one counseling with trained psychologist and social worker. Most of the women emphasized the importance of finding regular employment for their husbands from treatment and requested assistance in doing so.

Government involvement would be required in order to establish proper rehabilitation centers with follow up and after care services. Relevant NGOs, in partnership with the government, can play an important role in helping the skill building process of rehabilitee drug user as well as securing employment. Many of the women interviewed were willing to work provided. It given an opportunity since most women wanted to educate their children they believed the steady employments would allow them to do so as well. All respondents suggested a network of home based handicrafts and embroidery which could be sold.

\section{Recommendations}

In view of its gravity drug abuse has emerged as a major issue of social welfare. Any approach to control the problem of drug addiction has to be a multi dimensional identification, referrals services, treatment, public awareness and education and rehabilitation aspects, besides controlling the supply of the illicit drug. There are some viable recommendation are as follows.

1. It is strongly recommended that to reduce the demand for illicit drug through preventive education campaign for awareness certain to reach the maximum population of the country especially at risk groups.

2. It is suggested that to involve NGO's and community through lemma, local leaders, teacher, and family for preventive measures as well as treatment and rehabilitation programmes.

3. It is suggested that meaning full participation of mass media both print and electronic program can create awareness against drugs abuse and relevant business. 
4. It is fact that, the drug addiction is a core mechanism to a number of stresses and social problems, alternative coring mechanism should be evolved such as sports activities, ground facility, promote creative hobbies, confidence building training, stress management, skill development and meaningful employment.

5. It is suggested that the department of social welfare should bound to all social welfare should bound to all registered treatment centers to submit their activity reports and on the other hand the department must timely upgrade its data regarding drug abuse, addict and their families.

6. It is suggested that along with the youth, the returned or old age citizens should be motivated to participate in this social issue.

7. Good quality of standard drug treatment should provide by the Govt. on the affordable or free of cost.

8. It is suggested that Networking should maintain among the relevant NGOS to establish and facilitate appropriate mechanism for income generation for the spouses of drug users.

9. It is suggested that availability of a wider range of accessible female friendly service including reproductive health, family, planning, counseling etc

10. It is suggested that promoting awareness of existing nonprofit education institutions which provide low cost quality education. The option of adult literacy classes should also be made available to the spouses of drug user.

11. Parents need to play a crucial role in controlling drug usage among their children.

12. The teachers too can help much in the prevention of drug abuse. They can discuss danger of drug abuse, involve students in healthy and interesting activities, and give them career counseling.

\section{End Notes}

1. Global assessment program on drug abuse in Pakistan, UNODC 2000, conducted by the narcotics control division, Anti Narcotics Force.

2. National assessment report on drug use problem in Pakistan, UNODC 2006, conducted by the narcotics control division, Anti Narcotics Force.

3. National drug abuse assessment study of Pakistan 2008 to 20011, a review done by Anti Narcotics Force. http:/enwikipedia.org/wiki/ant-narcotics force accessed on $2 / 5 / 2013$.

\section{References}

Adams, B.N (1985) the family: A sociological interpretation, Chicago Rand McNally.

Ausubel D.P (1985) drug addictions, Random house, Newyork.

Craig Wilson Lecory (1999) case study in social work practice, books/Cole. 
Emmanuel, Zafar (2002) commentaries of control of narcotics substances Act 1997, Lahore our press. Grander press.

Harbin, H.T and Mazia H.M (1975). The family of drug abuses. A literature review, family process.

HIV second Generation surveillance in Pakistan national report III, national AIDS control programme, 2008.

James G. Barber (2002), social work with addictions, $2^{\text {nd }}$ : London, Palgrave Macmillan.

Kaufmann E and Kaufmann p (1979) family therapy of drug and alcohol abuse.

Kerivanek, J-A (1982) drug problems people problems, cause, treatment and prevention, Sydney, Allen and unwin.

Parshant Saroj (1993), drug abuse and society: New Delhi, Ashish publishing house.

Rapid situation and response assessment of drug related HIV in Pakistan 2008, Islamabad, Pakistan, and UNODC.

Reducing HIV stigma and discrimination: a critical part of national AIDS programmes 2007.

The hidden truth (2008), a study of HIV vulnerability, risk factors and prevalence among men injecting drugs and their wives: Nai Zindagi.

Women \& HIV/AIDS (2004) Experiences and consequences of stigma and discrimination, Nepal, Family health international.

World health organization (1969) WHO expert committee on drug dependence $16^{\text {th }}$ report (technical report series 407) Geneva: WHO

World health organization (1993) WHO expert committee drug dependence $28^{\text {th }}$ report (technical report series 836) Geneva :WHO

Dr. Syeda Farhana Sarfaraz is Assistant Professor in the Department of Social Work, University of Karachi. 